\title{
A clinical-pathological and survival study of oral squamous cell carcinomas from a population of the north of Portugal
}

\author{
Luís-Silva Monteiro ${ }^{1}$, José-Barbas do Amaral ${ }^{2}$, José-Ramón Vizcaíno ${ }^{3}$, Carlos-Alberto Lopes ${ }^{4}$, Fernando- \\ Oliveira Torres $^{5}$
}

\author{
${ }^{1} \mathrm{PhD}, \mathrm{MSc}$, DDS. Medicine and Oral Surgery Department, Dental Sciences Group - Health Sciences Research Centre, Instituto \\ Superior de Ciências da Saúde Norte, CESPU, Paredes, Portugal \\ ${ }^{2} \mathrm{PhD}, \mathrm{MD}$. Stomatology Department, Centro Hospitalar do Porto, Hospital de Santo António-Porto, Portugal \\ ${ }^{3}$ MD. Pathology Department, Centro Hospitalar do Porto, Hospital de Santo António-Porto, Portugal \\ ${ }^{4} \mathrm{PhD}$, MD. Molecular Pathology and Immunology Department, Instituto de Ciências Biomédicas Abel Salazar (ICBAS), Porto \\ University, Porto, Portugal \\ ${ }^{5}$ PhD, MD. Pathology Department, Instituto Superior de Ciências da Saúde Norte, CESPU, Paredes, Portugal
}

Correspondence:

Instituto Superior de Ciências da Saúde Norte, CESPU

Rua Central de Gandra, 1317

4585-116 Gandra PRD, Portugal

lmonteiro.md@gmail.com

Received: 28/01/2013 Accepted: 30/05/2013

\author{
Monteiro LS, Amaral JB, Vizcaíno JR, Lopes CA, Torres FO. A clinical- \\ pathological and survival study of oral squamous cell carcinomas from a \\ population of the north of Portugal. Med Oral Patol Oral Cir Bucal. 2014 \\ Mar 1;19 (2):e120-6. \\ http://www.medicinaoral.com/medoralfree01/v19i2/medoralv19i2p120.pdf

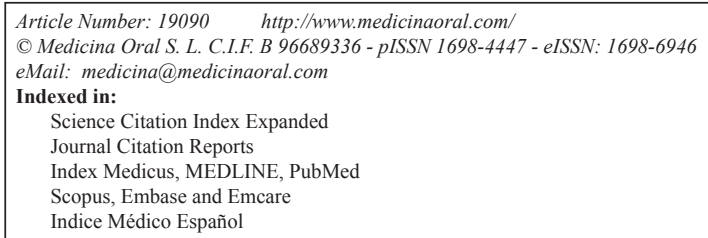

\begin{abstract}
Objectives: Our aim was to analyze the clinical, pathological, and outcome characteristics of oral squamous cell carcinomas (OSCC) from a population of the north of Portugal.

Material and Methods: We conducted a descriptive study of 128 OSCC diagnosed between the years of 2000 and 2010 in the Centro Hospitalar do Porto. Through of the review of the clinical records we studied several clinical, pathological, and outcome variables. The overall survival (OS) and disease-free survival (DFS) were analyzed by Kaplan-Meier method and log-rank test. Cox regression method was used for multivariate analysis.

Results: Of 128 patients with OSCC, $83(64.8 \%)$ were male and $45(35.2 \%)$ were female, (mean age of $62.13 \pm 15.57$ years). The most affected location was the tongue ( $\mathrm{n}=52 ; 40.6 \%)$. The most common cause of reference was a nonhealing ulcer $(\mathrm{n}=35 ; 28.9 \%)$ followed by oral pain $(\mathrm{n}=27 ; 22.3 \%)$. Sixty $(60.6 \%)$ patients were tobacco consumers and $55(57.3 \%)$ alcohol consumers. The cumulative 3 -years OS rate was $58.6 \%$ and DFS was $55.4 \%$. In multivariable analysis for OS, we found an adverse independent prognostic value for advanced tumour size $(\mathrm{p}<0.001)$ and for the presence of perineural permeation $(\mathrm{p}=0.012)$. For DFS, advanced stage tumours presented adverse independent prognostic value $(\mathrm{p}<0.001)$.

Conclusions: OSCC occurred most frequently in males, in older patients, and in patients with tobacco and/or alcohol habits. TNM and tumour stage additionally to the perineural permeation were the most important prognostic factors for the survival of these patients, contributing to identify high-risk subgroups and to guide therapy.
\end{abstract}

Key words: Squamous cell carcinoma, mouth neoplasms, oral cancer, oral pathology, prognosis. 


\section{Introduction}

Oral cancer is a major public health problem worldwide. Oral and pharyngeal grouped together are the sixth most common cancers in the world (1). An estimated 263,900 new cases and 128,000 deaths from lip and oral cavity cancer occurred in the year of 2008 worldwide (2). In Portugal, a total of 1200 cases of lip, oral and oropharynx cancers were reported in 2007, 949 (78.61\%) in males and 251 (21.4\%) in females. Moreover, in the last decade there has been an increasing trend for oral cancer in Portuguese population in both sexes and especially in the female group (3).

Almost $90 \%$ of oral cancers are squamous cell carcinomas (3). Smoking, alcohol use, and HPV infections are the major risk factors, with an attributable risk of oral cancer due to both tobacco and alcohol of $80 \%$ (4).

Despite recent advances in the detection and treatment of cancer, visual accessibility of the oral mucosa and the scientific knowledge on cancer risk factors, oral cancer carried a low survival rate (near 50\%) in the last few decades (1).

Treatment consists mainly in surgery, radiotherapy and/ or chemotherapy (5). However these treatment modalities are often associated with collateral effects that diminish considerably the quality of life of the patients (6). Therefore is important to identify and stratify patients with greater precision to the most appropriate choice of a treatment plan, avoiding excessive treatment in patients with low risk of recurrence and excessively conservative treatments in patients in whom the risk of recurrence is high.

The purpose of this study is to examine the clinical and pathological characteristics of oral squamous cell carcinomas (OSCC) and analyze their influence in the outcome of these patients.

\section{Material and Methods}

\section{-Patients population}

This was a retrospective study of 128 consecutive patients diagnosed and treated for primary OSCC at the Centro Hospitalar do Porto - Hospital de Santo António, Porto, Portugal, between 2000 and 2010. The study was approved and performed according to the institutional review board of the hospital. We include all consecutive primary OSCC located in the lip mucosa or oral cavity (C00.3-C00.5, C01-06). Patients were excluded when lacking relevant clinical and follow-up information or without histological confirmation of their diagnosis. From patient's records we obtained patient's age, gender, tumour location, first clinical manifestation of the disease, clinical tumour presentation, history of potentially malignant disorders, tobacco and alcohol habits, tumour stage, primary treatment, tumour grade, surgical margin status, vascular, lymphatic and perineural invasion, and follow-up information.
The tobacco and alcohol habits were categorized into the groups: consumers, non consumers and ex-consumers. Patients who smoked cigarettes (or equivalents) at the rate of 20 or more per day were considered heavy smokers (7). Those who drank alcohol at $30.0 \mathrm{~g} /$ day or more (for men) or $15.0 \mathrm{~g} /$ day or more (for women) were considered as heavy drinkers.

Tumour stage was reclassified according to the $7^{\text {th }}$ edition of the classification of malignant tumours of American Joint Committee on Cancer (8).

Treatment options were registered and grouped for statistical analysis into the categories: 1 - surgery alone; 2 - surgery and adjunctive radiotherapy (external-beam radiotherapy, 55-66Gy); 3 - chemotherapy (5-fluorouracil and cisplatin) followed by surgery; 4 - chemotherapy followed by surgery and adjunctive radiotherapy; 5 - other treatments including radiotherapy alone, chemotherapy alone or chemoradiotherapy; and 6 - support treatment. Hematoxylin-eosin-stained slides were available for all tumours to confirm the initial diagnosis. Tumour grade was reclassified into well differentiated (G1), moderately differentiated (G2), and poorly differentiated (G3) OSCC. Inspection for possible presence of vascular (venous), lymphatic and perineural invasion reported as present or absent, was performed on each sample. Surgical margin were classified according Sutton et al. (9). -Statistical analysis

The descriptive results were reported as absolute and relative frequencies. Associations between categorical variables were analysed using Chi-square test. Overall survival (OS) was defined as the time interval (months) between primary treatment and death by oral cancer or last follow-up. Disease-free survival (DFS) was defined as the time interval (months) between primary treatment and the first recurrence (whether local, regional or distant). The Kaplan-Meier method was used to plot survival curves and their prognostic effect was tested using the log-rank test. Variables with significant effects in the univariate analyses were entered into Cox proportional hazards model to investigate the independent effects of these variables.

Differences were considered statistically significant at $\mathrm{p}<0.05$. Statistical analyses were carried out using IBM SPSS Statistics version 21.0 software (IBM Corporation, NY, US).

\section{Results}

-Clinical and pathological findings

The study group included 128 patients, 83 men (64.8\%) and 45 women (35.2\%), with a ratio male:female of 1.8:1, whose ages ranged from 21 to 96 years, with a mean age of $62.13 \pm 15.57$ years. There were 17 (13.3\%) cases below the 45 years of age. Men were younger than women. Fifty men $(60.2 \%)$ were under 62 years and $32(71.1 \%)$ women had more than 62 years old $(\mathrm{p}=0.001)$. 
The most common clinical manifestation that brought the patient to the hospital was a non-healing ulcer in 35 cases $(31.8 \%)$ followed by oral pain $(n=27 ; 24.5 \%)$, odynophagia $(n=12 ; 10.9 \%)$, mass or nodule $(n=11 ; 10 \%)$, persistent white or red patch $(n=7 ; 6.4 \%)$, dysphagia $(n=6$; $5.5 \%)$, cervical mass $(n=5 ; 4.5 \%)$, prosthesis that fails to fit $(n=3 ; 3.6 \%)$, oral haemorrhage $(n=2 ; 1.8 \%)$, trismus $(\mathrm{n}=1 ; 0.9 \% \%)$, and foreign body sensation in one patient $(0.9 \%)$. This information was unknown in 18 cases.

The most frequently affected location was the tongue $(n=52 ; 40.6 \%)$ followed by the floor of the mouth $(n=19$; $14.8 \%)$, gingiva $(n=15 ; 11.7 \%)$, hard palate $(n=10 ; 7.8 \%)$, retromolar region $(n=13 ; 10.2 \%)$, labial mucosa $(n=11$; $8.6 \%)$, and buccal mucosa $(n=8 ; 6.3 \%)$.

In the cases with tobacco information $(n=99)$ we found the report of tobacco consumption in $60(60.6 \%)$ patients, of which $58(58.6 \%)$ were heavy smokers. Seven (7.1\%) patients were tobacco ex-consumers and 32 (32.3\%) were non consumers. Alcohol consumption was registered in 55 (57.3\%) patients of whom $43(44.8 \%)$ were heavy drinkers. Forty $(41.7 \%)$ patients were alcohol non consumers and one (1\%) patient was ex-consumer. In 32 cases alcohol information was not available. Forty-two (43.8\%) patients had simultaneous tobacco and alcohol consumption of which $36(37.5 \%)$ were both heavy smokers and heavy drinkers. The relation between tobacco and alcohol habits with age, gender and tumour location is shown in table 1 . We found a higher prevalence of smokers in males $(p<0.001)$, and in the youngest age group $(p<0.001)$. Moreover, males showed predominant alcohol misuse habits comparing to females $(p<0.001)$. More than a half of the patients with tumours located on the floor of the mouth, retromolar trigone, and tongue were tobacco consumers (Table 1).
On the first intra-oral clinical examination, the tumour had an ulcer presentation in 55 cases $(46.6 \%)$, an exophytic (verruciform) appearance in 19 (16.1\%) cases, an ulcer-exophytic appearance in $37(31.4 \%)$ cases and a patch (white or red) presentation in $7(5.9 \%)$ cases in the 118 cases with this information. History of leukoplakia was recorded in $17(13.3 \%)$ cases, erythroplakia in 3 $(2.3 \%)$ and actinic cheilitis (on lip) in $3(2.3 \%)$ cases.

Tumours were $\mathrm{T} 1$ in 34 cases $(26.6 \%)$, T2 in 47 cases (36.7\%), T3 in 10 cases $(7.8 \%)$, T4a in 31 cases $(24.2 \%)$, and T4b in 6 cases $(4.7 \%)$. Fifty patients $(39 \%)$ had tumour nodal involvement. N1 status was found in 19 (14.8\%) patients, N2 in 26 patients $(20.3 \%)$, and N3 in 5 patients $(3.9 \%)$. One subject $(0.8 \%)$ had a distant metastasis (lung) at time of diagnosis.

In the view of this, 26 patients $(20.3 \%)$ presented stage-I tumours, 32 patients (25\%) had stage-II tumours, 20 patients $(15.6 \%)$ presented stage-III tumours, 40 patients $(31.3 \%)$ had stage-IVA tumours, 9 (7\%) stage-IVB tumours, and one $(0.8 \%)$ had a stage-IVC tumour.

Fifty-eight patients $(45.3 \%)$ were treated with surgery alone, $37(28.9 \%)$ with surgery and adjunctive radiotherapy, $3(2.3 \%)$ with chemotherapy followed by surgery, $7(5.5 \%)$ with chemotherapy followed by surgery and adjunctive radiotherapy, and 10 (7.8\%) with other treatments including radiotherapy alone, chemotherapy alone or chemoradiotherapy. Thirteen patients (10.2\%) received only support treatment.

Tumours were graded as well-differentiated in 74 (57.8\%) cases, moderately differentiated in $45(35.2 \%)$, and poorly differentiated in $9(7 \%)$ cases. Of the 105 patients submitted to surgery, there were 60 cases with report of surgical margin status. Eleven (18.3\%) patients had tumour cells in the surgical margins, 33 (55\%) were free of tumour cells,

Table 1. Associations between tobacco/alcohol habits with age, gender and tumour location.

\begin{tabular}{|c|c|c|c|c|c|c|c|c|}
\hline & \multicolumn{4}{|c|}{ Tobacco } & \multicolumn{4}{|c|}{ Alcohol } \\
\hline & \multicolumn{2}{|c|}{ Consumer } & \multicolumn{2}{|c|}{ Heavy smoker } & \multicolumn{2}{|c|}{ Consumer } & \multicolumn{2}{|c|}{ Heavy drinker } \\
\hline & $\begin{array}{c}\text { No } \\
\text { (n; \%) }\end{array}$ & $\begin{array}{c}\text { Yes } \\
(n ; \%)\end{array}$ & $\begin{array}{c}\text { No } \\
\text { (n; \%) }\end{array}$ & $\begin{array}{c}\text { Yes } \\
(n ; \%)\end{array}$ & $\begin{array}{c}\text { No } \\
\text { (n; \%) }\end{array}$ & $\begin{array}{c}\text { Yes } \\
(n ; \%)\end{array}$ & $\begin{array}{c}\text { No } \\
\text { (n; \%) }\end{array}$ & $\begin{array}{c}\text { Yes } \\
(n ; \%)\end{array}$ \\
\hline \multicolumn{9}{|l|}{ Age } \\
\hline$<49$ years & $7(23.3)$ & $23(76.7)$ & $7(23.3)$ & $23(76.7)$ & $11(36.7)$ & $19(63.3)$ & $14(46.5)$ & $16(53.3)$ \\
\hline $49-63$ years & $8(26.7)$ & $22(73.3)$ & $10(33.3)$ & $20(66.7)$ & $9(34.6)$ & $17(65.4)$ & $13(50)$ & $13(50)$ \\
\hline 64-74 years & $7(36.8)$ & $12(63.2)$ & $7(36.8)$ & $12(63.2)$ & $9(45)$ & $11(55)$ & $11(55)$ & $9(45)$ \\
\hline$>75$ years & $17(85)$ & $3(15)$ & $1785)$ & $3(15)$ & $12(60)$ & $8(40)$ & $15(75)$ & $5(25)$ \\
\hline p-value & \multicolumn{2}{|c|}{$<0.001$} & \multicolumn{2}{|c|}{$<0.001$} & \multicolumn{2}{|c|}{0.304} & \multicolumn{2}{|c|}{0.227} \\
\hline \multicolumn{9}{|l|}{ Gender } \\
\hline Female & $19(76)$ & $6(24)$ & $20(80)$ & $5(20)$ & $19(76)$ & $6(24)$ & $21(84)$ & $4(16)$ \\
\hline Male & $20(27)$ & $54(73)$ & $21(28.4)$ & $53(71.6)$ & $22(31)$ & $49(69)$ & $32(45.1)$ & $39(54.9)$ \\
\hline p-value & \multicolumn{2}{|c|}{$<0.001$} & \multicolumn{2}{|c|}{$<0.001$} & \multicolumn{2}{|c|}{$<0.001$} & \multicolumn{2}{|c|}{0.01} \\
\hline \multicolumn{9}{|l|}{ Location } \\
\hline Labial mucosa & $3(75)$ & $1(25)$ & $3(75)$ & $1(25)$ & $3(50)$ & $3(50)$ & $3(50)$ & $3(50)$ \\
\hline Floor of the mouth & 0 & $19(100)$ & $1(5.3)$ & $18(94.7)$ & $4(23.5)$ & $13(76.5)$ & $5(29.4)$ & $12(70.6)$ \\
\hline Tongue & $19(46.3)$ & $22(53.7)$ & $20(48.8)$ & $21(51.2)$ & $23(56.1)$ & $18(43.9)$ & $29(70.7)$ & $12(29.3)$ \\
\hline Buccal mucosa & $4(80)$ & $1(2)$ & $4(80)$ & $1(20)$ & $2(50)$ & $2(50)$ & $3(75)$ & $1(25)$ \\
\hline Retromolar trigone & $3(25)$ & $9(75)$ & $3(25)$ & $9(75)$ & $2(18.2)$ & $9(81.8)$ & $4(36.4)$ & $7(63.6)$ \\
\hline Hard palate & $4(50)$ & $4(50)$ & $4(50)$ & $4(50)$ & $3(33.3)$ & $6(66.7)$ & $4(44.4)$ & $5(55.6)$ \\
\hline Gingiva & $6(60)$ & $4(40)$ & $6(60)$ & $4(40)$ & $4(50)$ & $4(50)$ & $5(63.5)$ & $3(37.5)$ \\
\hline p-value & \multicolumn{2}{|c|}{0.001} & \multicolumn{2}{|c|}{0.04} & \multicolumn{2}{|c|}{0.175} & \multicolumn{2}{|c|}{0.076} \\
\hline
\end{tabular}


and $16(26.7 \%)$ were close to tumour cells. We found vascular invasion in $11(11.2 \%)$ cases, perineural permeation in $14(14.3 \%)$ cases, and lymphatic invasion in 19 (19.4\%) in the 98 cases wherethis analysis was available.

\section{-Clinical Outcome}

At the end of our study, 68 patients (53.1\%) were alive without oral cancer, 2 patients $(1.6 \%)$ were alive with oral cancer, $56(43.8 \%)$ had died as a result of the oral cancer and 2 patients $(1.6 \%)$ had died as a result of other noncancer disease. The follow-up mean for all patients was $33.2 \pm 28.8$ months. The cumulative 3 -years OS rate was $58.6 \%$ and DFS was 55.4\%. At 5-years OS and DFS rates corresponded to $50.5 \%$ and $49.5 \%$, respectively (Fig. 1). In univariable analysis, tumour location $(\mathrm{p}=0.034)$, T status $(\mathrm{p}<0.001)$ (Fig. 2$), \mathrm{N}$ status $(\mathrm{p}<0.001)$, clinical stage $(p<0.001)$, surgical margins $(p=0.001)$, treatment option $(p<0.001)$, histological grade $(p<0.001)$, vascular invasion $(\mathrm{p}=0.005)$, and perineural permeation $(\mathrm{p}<0.001)$ (Fig. 2) were statistically correlated to OS. The same was observed with reference to DFS for $\mathrm{T}$ status $(\mathrm{p}=0.001), \mathrm{N}$ status $(\mathrm{p}<0.001)$, clinical stage $(p<0.001)$ (Fig. 3), treatment option $(p=0.01)$, surgical margins $(p=0.038)$, histological grade $(p=0.041)$, and perineural permeation $(\mathrm{p}=0.007)$ (Table 2$)$.

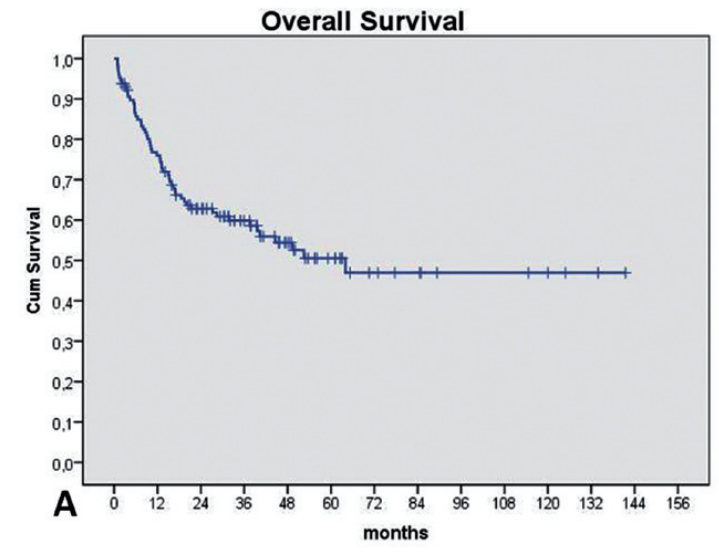

In multivariable analysis for OS, we found an adverse independent prognostic value for advanced tumour size (T) and for the presence of perineural permeation (Table 3). For DFS, advanced clinical stage presented adverse independent prognostic value (Table 4).

\section{Discussion}

Few studies have characterised oral cancers in the Portuguese population $(10,11)$. With this in mind, we analysed the clinical and pathological features and the outcome of a series of patients with OSCC from a central hospital in the north of Portugal.

We observed that oral cancer was twice more frequent in males than females (ratio 1.8:1) which is in accordance with the predominant male frequency of this cancer reported in literature (12). However this ratio was lower than the reported by others $(10,11,13,14)$. This could be attributed to the increasing trend of oral cancer in women in Portugal or simply be a result of sample constitution (3). The mean age (62 years) found in the present study is compatible with the majority of the published studies $(10,12,15)$. There were $13.3 \%$ of the patients with less than 45 year-old, result that has been described with increasing frequency in the literature (16-18).

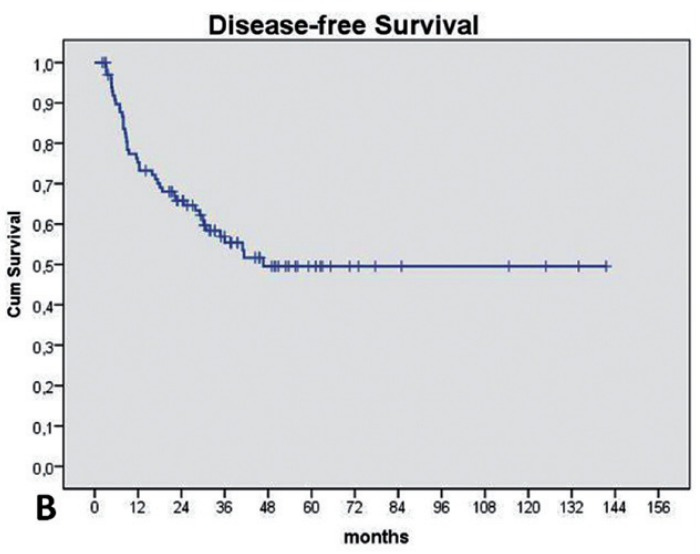

Fig. 1. Kaplan-Meier plots to overall survival (A) and disease-free survival (B).
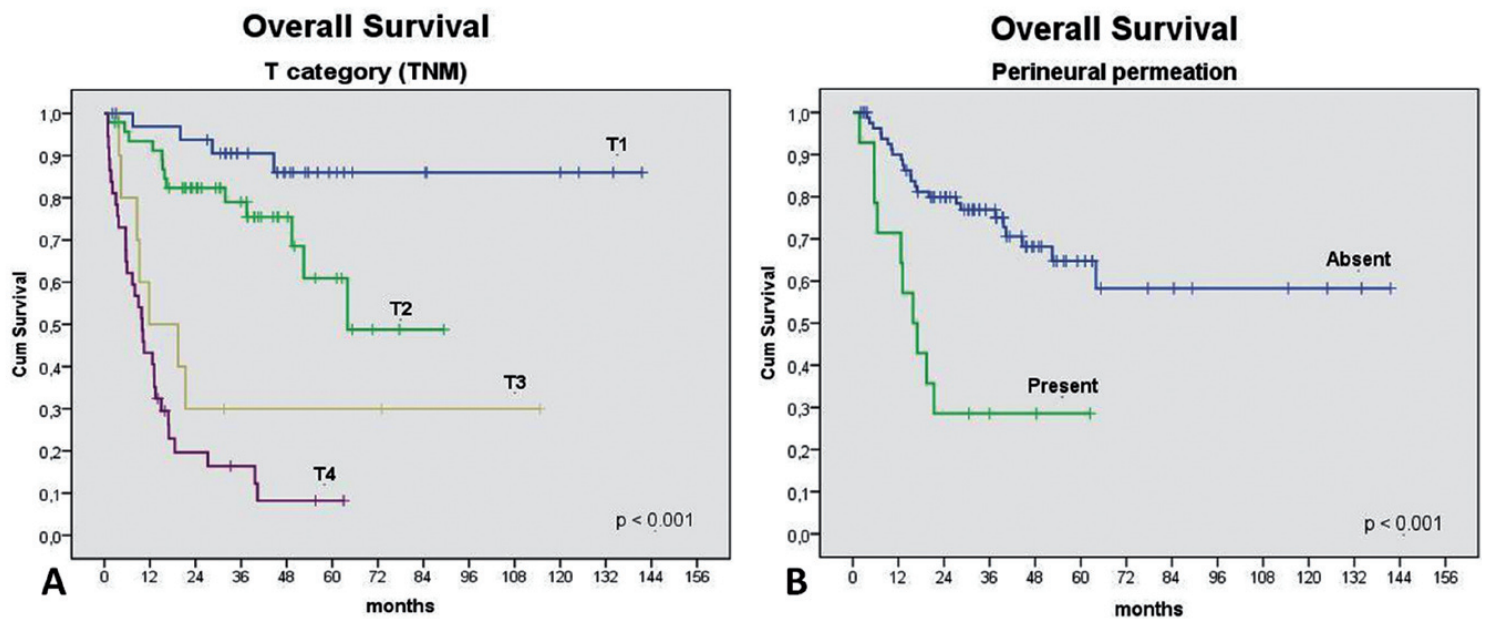

Fig. 2. Kaplan-Meier plots to overall survival according T category of TNM classification (A) and perineural permeation (B). 
Table 2. Kaplan-Meier estimates of probability of overall survival and disease-free survival at 3 years of follow-up (univariate analysis).

\begin{tabular}{|c|c|c|c|c|c|c|c|c|}
\hline Variable & $\mathbf{N}$ & dead & OS & p-value & $\mathbf{N}$ & recurrence & DFS & $p$-value \\
\hline \multicolumn{9}{|l|}{ Gender } \\
\hline Female & 45 & 17 & 62.9 & 0.439 & 37 & 17 & 56.7 & 0.609 \\
\hline Male & 83 & 39 & 58.1 & & 64 & 27 & 56.7 & \\
\hline \multicolumn{9}{|l|}{ Age } \\
\hline$<49$ years & 32 & 17 & 58 & \multirow{4}{*}{0.814} & 24 & 12 & 49.5 & \multirow{4}{*}{0.721} \\
\hline 49-63 years & 34 & 15 & 57 & & 27 & 14 & 48 & \\
\hline $64-74$ years & 28 & 11 & 61.8 & & 22 & 8 & 59.9 & \\
\hline$>75$ years & 34 & 13 & 63 & & 28 & 10 & 66.5 & \\
\hline \multicolumn{9}{|l|}{ Tumour location } \\
\hline Labial mucosa & 11 & 1 & 90 & \multirow{7}{*}{0.034} & 11 & 2 & 80 & \multirow{7}{*}{0.244} \\
\hline Floor of the mouth & 19 & 11 & 52.1 & & 14 & 10 & 28.6 & \\
\hline Tongue & 52 & 18 & 66.2 & & 44 & 16 & 66 & \\
\hline Buccal mucosa & 8 & 4 & 62.5 & & 6 & 3 & 50 & \\
\hline Retromolar trigone & 13 & 7 & 59.2 & & 10 & 5 & 56 & \\
\hline Hard palate & 10 & 6 & 50 & & 6 & 3 & 44.4 & \\
\hline Gingiva & 15 & 9 & 34.4 & & 10 & 5 & 41.7 & \\
\hline \multicolumn{9}{|l|}{ Tobacco consumption } \\
\hline No & 39 & 19 & 56.2 & \multirow[t]{2}{*}{0.860} & 31 & 15 & 51.6 & \multirow[t]{2}{*}{0.411} \\
\hline Yes & 60 & 29 & 58 & & 46 & 21 & 54.4 & \\
\hline \multicolumn{9}{|l|}{ Heavy Smoking" } \\
\hline No & 41 & 20 & 55.9 & & 33 & 17 & 47.2 & 0.229 \\
\hline Yes & 58 & 28 & 58.3 & 0.811 & 44 & 19 & 57.7 & \\
\hline Alcohol consumption & & & & & & & & \\
\hline No & 41 & 19 & 54.8 & 0.963 & 33 & 16 & 48.7 & 0.417 \\
\hline Yes & 55 & 27 & 59.8 & & 42 & 18 & 57.7 & \\
\hline Heavy drinker ${ }^{*}$ & & & & & & & & \\
\hline No & 53 & 24 & 59.5 & 0.690 & 43 & 20 & 50.4 & 0.567 \\
\hline Yes & 43 & 22 & 55.7 & & 32 & 14 & 58.7 & \\
\hline T status & & & & & & & & \\
\hline $\mathrm{T} 1$ & 34 & 4 & 90.5 & & 34 & 10 & 67.5 & \\
\hline $\mathrm{T} 2$ & 47 & 13 & 79 & $<0.001$ & 46 & 19 & 60.3 & 0.001 \\
\hline $\mathrm{T} 3$ & 10 & 7 & 30 & & 6 & 4 & 33.3 & \\
\hline $\mathrm{T} 4(\mathrm{~T} 4 \mathrm{a}+\mathrm{T} 4 \mathrm{~b})$ & 37 & 32 & 16.4 & & 15 & 11 & 24 & \\
\hline N status & & & & & & & & \\
\hline 0 & 78 & 22 & 74.5 & & 68 & 21 & 68.5 & \\
\hline 1 & 19 & 10 & 55.3 & $<0.001$ & 15 & 10 & 45 & $<0.011$ \\
\hline 2 & 26 & 21 & 24.4 & & 16 & 12 & 18.8 & \\
\hline 3 & 5 & 3 & 40 & & 2 & 1 & 50 & \\
\hline Stage & & & & & & & & \\
\hline I & 26 & 2 & 95.8 & & 26 & 6 & 78.9 & \\
\hline II & 32 & 6 & 83.5 & $<0.001$ & 31 & 9 & 74.6 & $<0.001$ \\
\hline III & 20 & 8 & 67.9 & & 19 & 11 & 51.3 & \\
\hline IV (IVA+IVB+IVC) & 50 & 40 & 23.6 & & 25 & 18 & 23.5 & \\
\hline Treatment options & & & & & & & & \\
\hline SG & 58 & 9 & 87.2 & & 55 & 15 & 70.6 & \\
\hline $\mathrm{SG}+\mathrm{RT}$ & 37 & 20 & 55.2 & & 34 & 21 & 42.2 & \\
\hline $\mathrm{CT}+\mathrm{SG}$ & 3 & 2 & 33.3 & $<0.001$ & 2 & 1 & 50 & 0.010 \\
\hline $\mathrm{CT}+\mathrm{SG}+\mathrm{RT}$ & 7 & 4 & 57.1 & & 5 & 3 & 60 & \\
\hline $\mathrm{CT}$ or RT or RCT & 10 & 8 & 12.5 & & 5 & 4 & 20 & \\
\hline ST & 13 & 13 & 0 & & 0 & - & - & \\
\hline Tumour grade & & & & & & & & \\
\hline G1 & 74 & 21 & 74.5 & $<0.001$ & 62 & 22 & 66 & 0.041 \\
\hline $\mathrm{G} 2+\mathrm{G} 2$ & 54 & 35 & 41 & & 39 & 22 & 43 & \\
\hline Margin status" & & & & & & & & \\
\hline Free of tumour & 33 & 10 & 80 & & 30 & 9 & 72.5 & \\
\hline Close to the tumour & 16 & 6 & 66.7 & 0.782 & 16 & 10 & 35.7 & 0.063 \\
\hline With tumour & 11 & 5 & 70.7 & & 10 & 6 & 32 & \\
\hline Vascular invasion ${ }^{*}$ & & & & & & & & \\
\hline Absent & 87 & 27 & 74.2 & 0.005 & 81 & 34 & 57.8 & 0.304 \\
\hline Present & 11 & 7 & 36.4 & & 9 & 5 & 44.4 & \\
\hline Perineural permeation* & & & & & & & & \\
\hline Absent & 84 & 24 & 76.6 & $<0.001$ & 79 & 31 & 60.4 & 0.007 \\
\hline Present & 14 & 10 & 28.6 & & 11 & 8 & 27.3 & \\
\hline Lymphatic invasion" & & & & & & & & \\
\hline Absent & 79 & 25 & 74.3 & 0.082 & 72 & 29 & 60.2 & 0.091 \\
\hline Present & 19 & 9 & 51.5 & & 18 & 10 & 44.4 & \\
\hline
\end{tabular}

OS, overall survival; DFS, disease-free survival; SG, surgery; RT, radiotherapy; CT, chemotherapy; RCT, chemoradiotherapy; ST, support treatment *information not available for every patient.

Tobacco and/or alcohol habits were present in more than a half of the patients and were predominant in males. This is an expected result in squamous cell carcinomas of the oral cavity, reflecting the importance of these habits as risk factors in oral cancer $(4,10)$. Therefore, primary prevention measures must be strengthened to a decrease of such habits.

In the last decades, an important role of HPV on the aetiology of oral cancer has been suggested (4). However, in many cases HPV detection in oral tumours 


\section{Disease-free Survival}

Clinical Stage

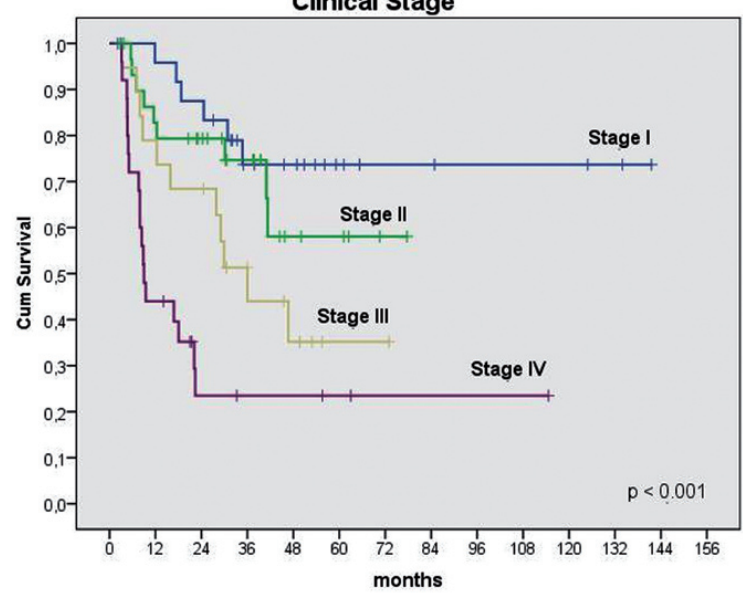

Fig. 3. Kaplan-Meier plots to disease-free survival according clinical tumour stage.
More than a half of the patients had an advanced tumour stage at presentation. This is in accordance with the results from other Portuguese studies (10) but contrast with some recent publications regarding oral cancer in Spain where most of patients had stage I or II tumours $(13,20)$. One of the reasons for this may be related with the possible low awareness of the population for oral cancer (7). The rates of OS and DFS at 60 months were $50.5 \%$ and $49.5 \%$, respectively, which are in accordance with the described survival rate for oral cancer in the most parts of the world $(1,12,21-23)$. However, recent US data showed a statistically significant improvement in overall survival among patients treated for OSCC from $54 \%$ in $1987-1989$ to $63 \%$ in the 2001-2007 timeframe (24).

Age and gender did not influence the OS and DFS, similar to the observed in several studies (25-27). Tobacco and alcohol consumption also did not influence the outcome of these patients, as observed by Vallecillo-Capilla et al. (13).

Table 3. Variables with significant independent effect in the multivariate Cox regression analysis of the overall survival.

\begin{tabular}{|l|c|c|c|}
\hline Variable & p-value $^{*}$ & HR $^{*}$ & $\mathbf{9 5 \%} \mathbf{C I}^{*}$ \\
\hline T status & & 1 & \\
T1 & 0.207 & 2.125 & $0.659-7.850$ \\
T2 & 0.019 & 5.654 & $1.332-33.991$ \\
T3 & $<0.001$ & 12.938 & $4.102-40.805$ \\
T4 (T4a+T4b) & & 1 & \\
\hline Perineural permeation & 0.012 & 2.784 & $1.251-6.194$ \\
Absent & & & \\
Present &
\end{tabular}

HR, hazard ratio; CI, confidence interval for HR.

*values adjusted for tumour location; $\mathrm{T}$ status; $\mathrm{N}$ status; clinical stage; treatment option; tumour grade; vascular invasion: and perineural permeation.

Table 4. Variables with significant independent effect in the multivariate Cox regression analysis of the disease-free survival.

\begin{tabular}{|l|c|c|c|}
\hline Variable & p-value $^{*}$ & HR $^{*}$ & $\mathbf{9 5 \%} \mathbf{C I}^{*}$ \\
\hline Stage & & & \\
I & & 1 & \\
II & 0.251 & 1.898 & $0.635-5.673$ \\
III & 0.026 & 3.464 & $1.158-10.360$ \\
IV (IVA+IVB) & $<0.001$ & 7.529 & $2.707-20.937$ \\
\hline
\end{tabular}

HR, hazard ratio; CI, confidence interval for HR.

*values adjusted for $\mathrm{T}$ status; $\mathrm{N}$ status; clinical stage; treatment option; tumour grade; and perineural permeation.

specimens is not routinely done probably due to the high cost of HPV DNA identification techniques. Some authors proposed p16 immunohistochemical detection as a marker of HPV infection (19). We think that this could be a more cost-effective option as a routine firstline marker of HPV in oral cancers specimens. It is our objective, in the future, to analyse HPV status with p16 immunostaining and with HPV in situ hybridization techniques in these tumours.
Tumour staging, using TNM classification, is the most common and accepted prognostic system for patients with cancer (28). Several studies have demonstrated the independent prognostic value of TNM classification on oral cancer $(13-15,29)$. We confirmed this in the present work. The $\mathrm{T}$ and $\mathrm{N}$ categories and the tumour stage showed a highly significant association with OS and DFS in the univariate analysis. In the multivariate ana-lysis T category had an independent prognostic value on the OS. 
Patients with T4 tumours showed a hazard ratio value 13 times higher than patients with T1 tumours. Tumour stage revealed an independent prognostic value in disease-free survival. Patients with stage IV tumours showed a hazard ratio value 8 times higher than patients with stage I tumours. Moreover as we already saw in this study, most of the patients were diagnosed in advanced stages already. This reflects the need for early diagnosis of this pathology at least in the north of Portugal. This is a concerning problem that needs to be strengthened in Portugal with several measures such as awareness and knowledge campaigns on oral cancer, and oral cancer screenings.

The histologic grade showed, in the present work, that well differentiated tumours had a better outcome on univariate analysis than less differentiated tumours. However, this variable lost significance in multivariate analysis. Nevertheless, Kademani et al (27) reported the independent value of the degree of cellular differentiation as a predictor of the survival of patients with OSCC.

The presence of perineural permeation was a strong indicator of an adverse OS with an independent effect on multivariate analysis. The perineural spread is reported at a frequency between 6 and 30\% in several head and neck carcinomas and regarded as an important prognosis factor (30).

In conclusion, this study indicates that OSCC occurred most frequently in males, in older patients, and in patients with tobacco and/or alcohol habits. Non-healing ulcers and oral pain were the most common reasons for the first clinical examination, very often in an advanced tumour stage. TNM and tumour stage classification and perineural permeation were the most important prognostic factors for the survival of these patients, contributing to identify high-risk subgroups and to guide therapy.

\section{References}

1. Warnakulasuriya S. Global epidemiology of oral and oropharyngeal cancer. Oral Oncol. 2009;45:309-16.

2. Jemal A, Bray F, Center MM, Ferlay J, Ward E, Forman D. Global cancer statistics. CA Cancer J Clin. 2011;61:69-90.

3. Monteiro LS, Antunes L, Bento MJ, Warnakulasuriya S. Incidence rates and trends of lip, oral and oro-pharyngeal cancers in Portugal. J Oral Pathol Med. 2013;42:345-51.

4. Warnakulasuriya S. Causes of oral cancer-an appraisal of controversies. Br Dent J. 2009;207:471-5.

5. Scully C, Bagan J. Oral squamous cell carcinoma overview. Oral Oncol. 2009;45:301-8.

6. Epstein JB, Thariat J, Bensadoun RJ, Barasch A, Murphy BA, Kolnick $\mathrm{L}$, et al. Oral complications of cancer and cancer therapy: from cancer treatment to survivorship. CA Cancer J Clin. 2012;62:400-22.

7. Monteiro LS, Salazar F, Pacheco J, Warnakulasuriya S. Oral cancer awareness and knowledge in the city of valongo, portugal. Int J Dent. 2012;2012:376838.

8. Brandwein-Gensler M, Smith RV. Prognostic indicators in head and neck oncology including the new 7th edition of the AJCC staging system. Head Neck Pathol. 2010;4:53-61.

9. Sutton DN, Brown JS, Rogers SN, Vaughan JA, Woolgar JA. The prognostic implications of the surgical margin in oral squamous cell carcinoma. Int J Oral Maxillofac Surg. 2003;32:30-4.

10. Dias GS, Almeida AP. A histological and clinical study on oral cancer: descriptive analyses of 365 cases. Med Oral Patol Oral Cir Bucal. 2007;12:E474-8.

11. Albuquerque R, López-López J, Marí-Roig A, Jané-Salas E, Roselló-Llabrés X, Santos JR. Oral tongue squamous cell carcinoma (OTSCC): alcohol and tobacco consumption versus non-consumption. A study in a Portuguese population. Braz Dent J. 2011;22:517-21.

12. Gorsky M, Epstein JB, Oakley C, Le ND, Hay J, StevensonMoore P. Carcinoma of the tongue: a case series analysis of clinical presentation, risk factors, staging, and outcome. Oral Surg Oral Med Oral Pathol Oral Radiol Endod. 2004;98:546-52.

13. Vallecillo-Capilla M, Romero-Olid MN, Olmedo-Gaya MV, Reyes-Botella C, Bustos-Ruiz V. Factors related to survival from oral cancer in an Andalusian population sample (Spain). Med Oral Patol Oral Cir Bucal. 2007;12:E518-23.

14 Choi KK, Kim MJ, Yun PY, Lee JH, Moon HS, Lee TR, et al. Independent prognostic factors of 861 cases of oral squamous cell carcinoma in Korean adults. Oral Oncol. 2006;42:208-17.

15. Sargeran K, Murtomaa H, Safavi SM, Vehkalahti MM, Teronen O. Survival after diagnosis of cancer of the oral cavity. Br J Oral Maxillofac Surg. 2008;46:187-91.

16. Llewellyn CD, Johnson NW, Warnakulasuriya KA. Risk factors for squamous cell carcinoma of the oral cavity in young people-a comprehensive literature review. Oral Oncol. 2001;37:401-18.

17. Shiboski CH, Schmidt BL, Jordan RC. Tongue and tonsil carcinoma: increasing trends in the U.S. population ages 20-44 years. Cancer. 2005;103:1843-9.

18. Conway DI, Stockton DL, Warnakulasuriya KA, Ogden G, Macpherson LM. Incidence of oral and oropharyngeal cancer in United Kingdom (1990-1999) - recent trends and regional variation. Oral Oncol. 2006;42:586-92.

19. Thomas J, Primeaux T. Is p16 immunohistochemistry a more cost-effective method for identification of human papilloma virusassociated head and neck squamous cell carcinoma? Ann Diagn Pathol. 2012;16:91-9.

20. Monteiro LS, Diniz-Freitas M, Garcia-Caballero T, Warnakulasuriya S, Forteza J, Fraga M. Combined cytoplasmic and membranous EGFR and p53 overexpression is a poor prognostic marker in early stage oral squamous cell carcinoma. J Oral Pathol Med. 2012;41:559-67.

21. Yeole BB, Ramanakumar AV, Sankaranarayanan R. Survival from oral cancer in Mumbai (Bombay), India. Cancer Causes Control. 2003;14:945-52. 22. Carvalho AL, Ikeda MK, Magrin J, Kowalski LP. Trends of oral and oropharyngeal cancer survival over five decades in 3267 patients treated in a single institution. Oral Oncol. 2004;40:71-6.

23. Carvalho AL, Singh B, Spiro RH, Kowalski LP, Shah JP. Cancer of the oral cavity: a comparison between institutions in a developing and a developed nation. Head Neck. 2004;26:31-8.

24. Siegel R, Naishadham D, Jemal A. Cancer statistics, 2012. CA Cancer J Clin. 2012;62:10-29.

25.Veness MJ, Morgan GJ, Sathiyaseelan Y, Gebski V. Anterior tongue cancer: age is not a predictor of outcome and should not alter treatment. ANZ J Surg. 2003;73:899-904.

26. Popovtzer AP, Shpitzer T, Bahar G, Marshak G, Ulanovski D, Feinmesser R. Squamous cell carcinoma of the oral tongue in young patients. Laryngoscope. 2004;114:915-7.

27. Kademani D, Bell RB, Bagheri S, Holmgren E, Dierks E, Potter B, et al. Prognostic factors in intraoral squamous cell carcinoma: the influence of histologic grade. J Oral Maxillofac Surg. 2005;63:1599-605.

28. van der Schroeff MP, Baatenburg de Jong RJ. Staging and prognosis in head and neck cancer. Oral Oncol. 2009:45:356-60.

29. Laimer K, Spizzo G, Gastl G, Obrist P, Brunhuber T, Fong D, et al. High EGFR expression predicts poor prognosis in patients with squamous cell carcinoma of the oral cavity and oropharynx: a TMAbased immunohistochemical analysis. Oral Oncol 2007;43:193-8.

30. Rahima B, Shingaki S, Nagata M, Saito S. Prognostic significance of perineural invasion in oral and oropharyngeal carcinoma. Oral Surg Oral Med Oral Pathol Oral Radiol Endod. 2004;97:423-31.

\section{Conflict of interest}

There are no potential conflicts of interest. 